\title{
Avances en el desarrollo de productos biológicos para el tratamiento de la adicción a las drogas y las sobredosis
}

\section{Advances in the Development of Biologics to Treat Drug Addictions and Overdose}

| IVÁN D. MONTOYA
Deputy Director. Division of Pharmacotherapies and Medical Consequences of Drug Abuse.

National Institute on Drug Abuse (NIDA)

Enviar correspondencia a:

Iván D. Montoya.

imontoya@mail.nih.gov

\section{Resumen}

La adicción a las drogas es un trastorno complejo que requiere diversos abordajes, entre los que está el uso de tratamientos farmacológicos. Actualmente, estas terapias se basan en "pequeñas" moléculas o sustancias quimicas que atraviesan la barrera hematoencefálica y actúan sobre los neurotransmisores. Desafortunadamente, con frecuencia no tienen la eficacia deseada o pueden causar efectos secundarios no deseados, que afectan especialmente el sistema nervioso central (SNC). Un enfoque novedoso es el uso de productos biológicos para el tratamiento de la adicción a las drogas. Los productos biológicos son generalmente moléculas complejas y "grandes", que no atraviesan la barrera hematoencefálica y por tanto, no tienen efectos sobre el SNC. En principio, parece que estos productos impiden el acceso de las drogas de abuso al cerebro, con lo cual se previene la activación de los sistemas de recompensa del cerebro $y$, en consecuencia, se produce la extinción de la adicción. Los tratamientos biológicos incluyen inmunoterapias, tales como las vacunas o los anticuerpos, así como también las enzimas. La aparición de nuevos productos, así como métodos de producción más modernos y eficientes, está posibilitando enormes oportunidades para avanzar en el descubrimiento y desarrollo de productos biológicos para el tratamiento de las adicciones, así como también de las sobredosis por drogas. Estos productos incluyen nuevas vacunas con mayor especificidad y capacidad de producir anticuerpos, nuevos métodos y técnicas para producir vacunas y anticuerpos, y nuevas enzimas butyrylcholinesterases con una alta eficiencia para metabolizar cocaina. El propósito de este artículo es proporcionar una visión general del desarrollo de productos biológicos para el tratamiento de adicción a las drogas y la sobredosis.

Palabras clave: Productos biológicos, vacunas, anticuerpos, enzimas, abuso de drogas, sobredosis.

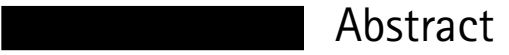

Drug addictions are complex disorders that require multiple approaches, including the use of pharmacotherapies. Currently, these therapies are based on "small" molecules or chemicals that penetrate the blood-brain barrier, reach the brain, and produce their effects on neurotransmitter systems. Unfortunately, they often do not have the desired efficacy or may cause undesirable side effects, especially at the central nervous system (CNS) level. A novel approach is the use of biologics to treat drug addictions. Biologics are usually complex and "large" molecules, which do not cross the blood-brain barrier and, thus, have no CNS effects. In principle, it appears that the efficacy of biologics to treat drug addiction is by preventing the access of the drug of abuse to the brain, preventing the activation of brain reward systems, and eventually producing the extinction of addiction. Biologic therapeutics includes immunotherapies, such as vaccines or antibodies, as well as enzymes. New products as well as new and more efficient methods of production, are offering vast opportunities to advance the discovery and development of biologics to treat addictions as well as drug overdose. These products include new vaccines with greater specificity and ability to produce antibodies, new methods and techniques to produce vaccines and antibodies, as well as new enzymes with high efficiency to metabolize cocaine. The purpose of the article is to provide a general overview of the development of biologics for the treatment of drug addictions and overdose.

Key words: Biologics, vaccines, antibodies, enzymes, drug abuse, overdose 
A ddictions to drugs are among the major public health problems in the world and require a coordinated effort to prevent and treat them. According to the 2010 National Survey on Drug Use and Health (NSDUH) of the United States, it has been estimated that 23.1 million individuals needed treatment for an illicit drug or alcohol use problem. Despite the large of individuals needing treatment, a small number of people seek drug abuse treatment because of the limited efficacy of the available interventions.

The treatment of drug addictions usually involves psychosocial interventions and sometimes the use of medications. At present, the success rates of pharmacotherapies for the different drug use disorders is low (Volkow, 2010). The only disorders that have medications approved by the FDA are nicotine and opiate use disorders, although their efficacy is considered modest. For nicotine dependence, only $5 \%$ of individuals treated for this disorder are able to quit for three to twelve months. For opiate dependence, the effect size of methadone maintenance interventions in reducing illicit opiate use is moderate (Marsch, 1998).

Given the large extent of the public health problem of drug addictions and the relative lack of safe and effective treatments, there is a great need to develop innovative approaches to treat these disorders. Until recently, most of the research effort was placed on the discovery and development of medications, also known as "small" molecules. These are chemically well-characterized compounds that are able to penetrate the blood-brain barrier, reach the brain, and produce their effects on neurotransmitter systems. Unfortunately, medications often do not have the desired efficacy or may cause undesirable side effects, especially at the central nervous system (CNS) level (Montoya \& Vocci, 2008).

A novel approach is the use of biological products, also known as biologics, to treat drug addictions and overdose. According to the Food and Drug Administration (FDA), "Biological product means a virus, therapeutic serum, toxin, antitoxin, vaccine, blood, blood component or derivative, allergenic product, or analogous product, or arsphenamine or derivative of arsphenamine (or any other trivalent organic arsenic compound), applicable to the prevention, treatment, or cure of a disease or condition of human beings" (U.S.Food and Drug Administration, 1999). Biologics are generally "large" molecules derived from living material, complex in structure, usually not fully characterized, do not cross the blood-brain barrier, and have no CNS effects. Biologics can be extracted from living systems (e.g., extracted from tissues), originated from stem cells, produced by recombinant DNA, produced in bio-reactors, or engineered in a laboratory.

Therapeutic biologics have made a significant impact on many areas in medicine; for example, oncology, rheumatology, dermatology, neurology and psychiatry. For addiction disorders biologics may offer safer and more efficacious ways to treat them. The suggested mechanism of the efficacy of biologics is by preventing the access of the drug of abuse to the brain. This may, in turn, prevent the activation of brain reward systems and eventually produce the extinction of the addictive behavior (Kosten et al., 2002; Montoya, 2008). Moreover, by preventing the access of the drug of abuse to the brain, biologics may also be an effective method to treat illicit drug overdose (Peterson \& Owens, 2009).

The biologics most widely investigated for drug addictions include vaccines, antibodies and enzymes. The notion of using biologics against drugs of abuse was first described in 1974 in a study conducted in monkeys that received morphine immunization and showed a reduction in heroin self-administration (Bonese, Wainer, Fitch, Rothberg, \& Schuster, 1974). Subsequently, biologics, particularly vaccines and monoclonal antibodies, have been investigated to treat SUDs such as nicotine, cocaine, methamphetamine, opiates, and phencyclidine use disorders (Kinsey, Jackson, \& Orson, 2009). More recently, engineered enzymes are being investigated to treat drug addiction, more specifically cocaine addiction (Zheng \& Zhan, 2009).

At present, vaccines have been investigated in animals and some in humans. Studies in animals have been conducted with vaccines for nicotine, cocaine, amphetamine, and heroin addiction. Human studies have been conducted with vaccines only for nicotine and cocaine addiction. The mechanism of action of the vaccines is based on a pharmacokinetic antagonism of the drug of abuse. Vaccines stimulate the immune system to identify the drug of abuse as an antigen (foreign substance). Although addictive drugs are too small to stimulate an immune response, they can be rendered immunogenic by conjugating them on to a foreign carrier protein through a linker arm. That way, the vaccine can defend the body from the effects of the drug of abuse by forming an antibody-antigen complex in plasma. This complex is a large molecule that is unlikely to cross the blood-brain barrier and, therefore, prevents the access of the drug to the brain. Because vaccines rely on the immune system to produce antibodies, they take longer time to produce the expected effect but have the advantage of blocking drugs from entering the brain longer than monoclonal antibodies. They also require the administration of boosters to maintain the desirable titer levels (Anton et al., 2009; Gentry, Ruedi-Bettschen, \& Owens, 2010; Orson et al., 2008; Peterson \& Owens, 2009).

Antibodies are being developed to treat drug addictions as well as drug overdose. Antibodies have the advantage of not needing the immune system to produce their effect. They bind directly to the drug of abuse and produce an almost immediate effect. The drawback is that antibodies may have a shorter half-life. Therefore, an antibody can be injected and rapidly block the effect of the drug before it reaches the brain. These effects make antibodies more suitable to treat drug overdose than to extinguish addictive behaviors (Gentry et al., 2010; Zheng \& Zhan, 2009; Carroll, Gao, Brimijoin, \& Anker, 2011).

Enzymes are a group of biologics that have the potential to be used to treat both drug addiction as well as overdose. Engineered enzymes are being developed with more efficiency to rapidly metabolize the drug of abuse before it reaches the brain than the wild enzyme. It has been suggested that enzymes may work better than an antibody or vaccine when the drug concentration in plasma is high, as is the case of an overdose. A vaccine may not be helpful because of the delay by the immune system to produce levels of antibody 
titers capable enough to antagonize the drug of abuse and the monoclonal antibody may not be helpful because it would be saturated by the drug of abuse. In both cases, a large proportion of the illicit drug molecules may still be free to access the central nervous system (Brimijoin et al., 2008; Gao, Orson, Kinsey, Kosten, \& Brimijoin, 2010; Godin, Shemesh-Davish, Sklair-Tavron, \& Rosenstock, 2012; Zheng et al., 2008).

Recent advances in the development of biologics, including gene therapy, bioengineer, and nanotechnology methods are providing a wealth of opportunities to discover and develop new biologics that are more potent and specific and with longer duration of action against drugs of abuse. The purpose of this article is to provide a general overview of the research of biologics, specifically vaccines, monoclonal antibodies, and enzymes for the treatment of addiction disorders as well as drug overdose. This review will focus on the treatment of addiction disorders associated with the use of nicotine, cocaine, methamphetamine, and opioids.

\section{Nicotine}

Biologics in the form of vaccines are being investigated to help smokers quit smoking and alleviate their nicotine dependence. The mechanism of action of the anti-nicotine vaccines is basically similar to the mechanism of other antidrug vaccines. The anti-nicotine vaccines are expected to produce nicotine-specific antibodies that bind nicotine in the blood and reduce nicotine uptake into the brain. Therefore, the brain reinforcing effects of nicotine are prevented and the behavioral mechanisms of addiction are eventually extinguished. The anti-nicotine vaccines being evaluated include NicVax ${ }^{\mathrm{TM}}$ (produced by Nabi Pharmaceuticals), NIC002 (Nicotine Qbeta therapeutic vaccine, Cytos Biotechnology), SEL-068 (Selecta Biosciences using a proprietary Synthetic Vaccine Particle [SVP' $\left.{ }^{\text {тм}}\right]$ ), TA-NIC vaccine (Celtic Pharma), and IP18-KLH (Niccine, investigators at the Karolinska Institute in Sweden and Independent Pharmaceutica).

\section{NicVAX}

The anti-nicotine vaccines have reached the most advanced phase of clinical evaluation. The NicVax developed by Nabi Biopharmaceuticals was recently evaluated in two Phase III clinical trials. This vaccine consists of the hapten 3'-aminomethylnicotine that has been conjugated to Pseudomonas aeruginosa exoprotein, which was made nontoxic by deletion of an amino acid. This vaccine showed good immunogenicity and appeared safe and effective, particularly among individuals who produced high antibody titers. A randomized, double-blinded, placebo-controlled multicenter clinical trial conducted in a sample of 301 smokers evaluated NicVAX at doses of 200- and 400- $\mu \mathrm{g}$ administered four or five times over a period of 6 months, as compared with placebo. The results showed that subjects with the highest serum anti-nicotine antibody response were significantly more likely to achieve 8 weeks of continuous abstinence from weeks 19 through 26 than those who received placebo injection (Hatsukami et al., 2011).

Nabi Pharmaceuticals recently completed two phase III clinical trials of the NicVAX ${ }^{\circledR}$ for smoking cessation. The design of these studies was double-blinded, placebo-controlled. The sample size of each one study was approximately 1,000 subjects. The primary outcome measure was the abstinence rate (defined by self-reported cigarette use and exhaled carbon monoxide measures) for 16 weeks ending at 12 months, The results of the first study were reported by the company on July, 2011 and showed that, although the vaccine was well-tolerated, the quit rate of subjects treated with NicVAX was similar (11\%) to those who received placebo. The company concluded that their vaccine did not meet its primary endpoint. A few months later, on November, 2011, Nabi Biopharmaceuticals announced the preliminary findings of the second Phase III clinical trial. They reported that the results were similar to the ones found in the previous Phase III trial. According to the Nabi Pharmaceuticals website (www.nabi. com), a clinical study testing varenicline in combination with NicVAX is ongoing and results are expected by the second half of 2012 (Nabi Pharmaceuticals, 2012).

\section{$\mathrm{NICO02}$}

The anti-nicotine vaccine NIC002 (Nicotine Qbeta therapeutic vaccine) is being developed by Cytos Biotechnology (http://www.cytos.com). Since April of 2007, it is under an exclusive license agreement with Novartis. This vaccine uses an antigen based on virus-like particles as the carrier protein, which are covalently coupled with nicotine. A placebo-controlled, clinical trial with NICOO2 at a dose of $100 \mu \mathrm{g}$ showed that this vaccine had good immunogenecity, was well tolerated, and showed efficacy in a sub-group of subjects. All study participants who received the vaccine developed anti-nicotine antibody titers while those in the placebo group did not show measurable anti-nicotine antibody titers. About $70 \%$ of the participants reported side effects but they were mostly mild (e.g., pain at the site of the injection, flu-like symptoms) and resolved within 24 hours after injection. The data analysis of the entire sample size did not show significant differences between the vaccine and placebo at the end of six months of treatment and after the 12-month follow-up period. However, a subgroup analysis showed that subject who achieved high antibody levels upon vaccination had statistically significant better smoking outcomes. These results were considered a clinical proof-ofconcept for NICOO2 (Cytos Biotechnology, 2012).

In November of 2010, Cytos Biotechnology was informed by Novartis that Duke University in collaboration with Wake Forest University received IND approval from the FDA to start a clinical study with NIC002 and funded by the National Institute on Drug Abuse (NIDA) of the National Institutes of Health $(\mathrm{NIH})$. This study is a phase II clinical trial $(n=65)$ to evaluate using PET the pharmacokinetics / pharmacodynamics of nicotine during cigarette smoking of 
cigarettes containing $11 \mathrm{C}$-nicotine in individuals treated with the vaccine. Subjects will receive 4 subcutaneous injections of $100 \mu \mathrm{g}$ of NIC002 in Alum vaccine at 4-week intervals (Cytos Biotechnology, 2012).

\section{SEL-068}

One of the reasons why clinical trials of the anti-nicotine vaccines failed is that they do not stimulate the immune system well enough to produce the required antibody levels that can prevent the access of nicotine to the brain. A new approach is using nano-technology methods to develop nano-particle based vaccines, which is expected to boost the production of anti-nicotine antibodies ( $\mathrm{Gu}$, Langer, \& Farokhzad, 2009; Zhang et al., 2008). Selecta Biosciences has a proprietary Synthetic Vaccine Particle (SVP'M) platform for vaccine development that allows both the development of new therapeutic applications and also vaccines with better efficacy and safety profiles. This vaccine consists of synthetic immunomodulatory nanoparticles that home to antigen presenting cells (dendritic cells and B cells) to produce highly efficient antigen-specific immune responses. This fully synthetic vaccine allows a modular design and appears to reduce the cost and time of development. The company has created a targeted Synthetic Vaccine Particles $\left(t_{S V P}{ }^{\text {тM }}\right)$ that activate immune responses to a wide array of relevant antigens, including small molecules, peptides, oligosaccharides, and proteins, including drugs of abuse. This synthetically engineered nanoparticle anti-nicotine vaccine focuses on the immune response to nicotine and, therefore, does not have the potential confounding responses associated to biological carriers used in traditional vaccine technologies.

A Phase I double-blind, placebo-controlled, ascending dose, clinical trial was initiated in November, 2011. The goal is to assess the concentrations of nicotine-specific antibodies in response to different doses of the vaccine, as well as the safety and possible efficacy for smoking cessation and relapse prevention. It is expected that this study will be completed in the first half of 2012. The development of this vaccine has been funded in part with a grant from the National Institute of Drug Abuse (NIDA) (Selecta Biosciences, 2012).

\section{TA-NIC}

TA-NIC vaccine produced by Celtic Pharma uses the cholera toxin-B subunit as a carrier protein (Celtic Pharma, 2012). According to clinicaltrials.gov, a multicenter, doubleblind, randomized, placebo-controlled, 3-arm, Phase 2, 52-week study evaluating the efficacy and safety of TA-NIC as an aid for smoking cessation is already completed. Subjects apparently received 7 injections from Weeks 0 to 16 of vaccine or placebo. They were also offered counseling sessions for their smoking cessation. The primary outcome measure is 4-week period of smoking abstinence at Week 26 as measured by self-reported smoking abstinence supported by carbon monoxide exhalation test data. Results do not appear to be published; however, reports in the news media suggest that the vaccine was not better than placebo. The company attribute this failure to problems with the manufacturing of the vaccine (Celtic Pharma, 2012).

\section{IP18-KLH (Niccine)}

Niccine is an anti-nicotine vaccine developed by Swedish investigators at the Karolinska Institute and Independent Pharmaceutica. This is a nicotine immunoconjugate IP18$\mathrm{KLH}$ that prevents the access of nicotine to the brain and has demonstrated to reduce the increase in dopamine output in the nucleus accumbens induced by nicotine as well as the reinstatement of nicotine-seeking behavior in rats. It has also been found that IP18-KLH not only did not precipitate but also ameliorate nicotine withdrawal in rats (de Villiers et al., 2010; de Villiers et al., 2002). Therefore, individuals treated with IP18-KLH may even have milder nicotine withdrawal symptoms when they quit smoking. It has been reported on the internet (Unknown, 2012) (http:// healthvox.info/? $p=33$ ) that this vaccine is being tested in 400 smokers in Nordic countries, but this reviewer could not find this trial in clinicaltrials.gov or other information about the clinical testing of this vaccine. Apparently, the company was liquidated in 2010 (cited in (Gorelick, 2012))

\section{Other approaches}

The efficacy of the anti-nicotine conjugate vaccine is limited by the unpredictable serum concentration of nicotine-specific antibodies that generate. Preliminary studies suggest that the combination of two nicotine immunogens that are structurally different may increase the production of antibodies because each vaccine may stimulate a different type of B-type lymphocytes. It has been reported that a combination of active (vaccine) and passive immunization appears to be more effective than treatment with a vaccine alone. Currently, studies are being conducted in animals evaluating the administration of monoclonal antibodies to rats that have already been vaccinated. However, the translation of the results is difficult because the generated amount of anti-nicotine antibodies remains unpredictable (Pravetoni et al., 2011; Pravetoni et al., 2012).

\section{Opiates}

The feasibility of a vaccine to pharmacokinetically block the access of opiates to the brain by using antibodybased antagonism was first describe in 1974. The results showed that monkeys trained to self-administer heroin and then treated with a morphine-6-hemisuccinyl-bovine serum albumin (BSA) vaccine conjugate had a reduction in heroin intake (Bonese et al., 1974). The development of immunotherapies for opiate addiction is particularly challenging because a potentially efficacious vaccine should be able to bind to its target(s) with high specificity and avoid interfering with the endogenous or medically prescribed 
opioids, generate sufficient antibody titers in a limited number of vaccine administrations, and prevent the access of abusable opioids to the brain. The ideal anti-opiate vaccine is one that can produce antibodies against heroin and its active metabolites without blocking the pharmacotherapeutic effects of other opiates such as methadone or buprenorphine, which are prescribed to treat opioid addiction or as analgesics. Moreover, heroin use represents an additional challenge as immunotherapeutic because it is metabolized to multiple psychoactive molecules and a vaccine should be able to bind to most or all of them.

Currently, several groups are investigating anti-opiate vaccines (Anton \& Leff, 2006; Anton et al., 2009; Li et al., 2011; Pravetoni et al., 2012; Stowe et al., 2011). One of them (M-TT), is being developed by a group of investigators in Mexico (Anton \& Leff, 2006; Anton et al., 2009). It appears to be a highly immunogenic bivalent morphine/ heroin vaccine. It uses the tetanus toxoid as protein carrier and studies conducted in rats have shown that the vaccine was able to prevent opiate use relapse. Currently, studies are being conducted to assure a reliable, stable, and highly immunogenic supply of this vaccine. The vaccine has been administered at 2 week intervals and the maximal titers have been achieved by the 4 th dose. Preliminary observations suggest good maintenance of antibody titers for up to 6 months after the last booster dose. This vaccine appears to show considerable initial promise for efficacy.

Vaccines for specific targets are limited to a number of structurally similar opioids. However, it is known that opioid uses often switch or transition their use across multiple different opioids. Therefore, a vaccine against a single target may only be partially efficacious. A strategy that targets several of the most commonly abused opioids can have great public health relevance. Investigators are studying morphine (M) and oxycodone (OXY) haptens conjugated to keyhole limpet hemocyanin (KLH) through tetraglycine (Gly)4 linkers (M-KLH) for the treatment of poly-opioid addiction. A recently published study conducted in rats showed that M-KLH alone produced high titers of antibodies directed against heroin, 6-monoacetylmorphine (6-MAM), and morphine. Also, immunization of rats with OXY-KLH produced high titers of antibodies against oxycodone and oxymorphone. Then, immunization with the bivalent vaccine produced high antibody titers against both immunogens. Moreover, the bivalent vaccine appears to have enhanced pharmacokinetic efficacy. Future studies are needed to determine the efficacy of bivalent anti-opioid vaccines that may simultaneously target multiple abusable opioids (Pravetoni, in press).

Oxycodone is the most widely abuse opiate prescription medication and oxycodone addiction has become an epidemic of great proportions. In 2010, approximately 598,000 individuals in the United States used oxycodone in the form of OxyContin ${ }^{\circledR}$ for non medical purposes (Substance Abuse and Mental Health Services Administration, 2011). Little research has been conducted to evaluate treatments for oxycodone addictions. A vaccine against oxycodone may be a therapeutic option for this public health problem.
A recent study reported the synthesis and evaluation in rats of the immunologic and pharmacokinetic effects of an oxycodone vaccine. Several candidate vaccines were evaluated and a lead candidate emerged. The OXY(Gly)4-KLH vaccine appear to affect the pharmacokinetics of oxycodone and to block its centrally mediated opioid effect. This vaccine warrants further investigation as a potential treatment for oxycodone addiction (Pravetoni et al., 2012).

\section{Cocaine}

Several groups of investigators are working in developing anti-cocaine vaccines (Fox et al., 1996; Hicks et al., 2011; Kantak, 2003; Kosten et al., 2002; Martell, Mitchell, Poling, Gonsai, \& Kosten, 2005), monoclonal antibodies, and enzymes to treat cocaine addiction or overdose. One of the vaccines, the TA-CD vaccine, has been evaluated in clinical trials. This vaccine is being developed by Celtic Pharma and it is similar to TA-NIC. It uses succinylnorcocaine coupled to a nontoxic subunit of recombinant cholera toxin $B$ and is administered with aluminum hydroxide as the adjuvant. A Phase Ilb clinical trial was conducted in a sample of 114 cocaine- and opioid-dependent outpatients who were receiving methadone treatment. Subjects received a dose of $360 \mu \mathrm{g}$ of vaccine (or placebo) at 0, 2, 4, 8 and 12 weeks, as well as weekly individual cognitive-behavioral therapy. The intent-to-treat analysis showed no significant difference in the proportion of cocaine-free urine samples between vaccine and placebo groups. However, it was found that subjects with the highest IgG antibody titers $(\geq 43 \mu \mathrm{g} / \mathrm{ml})$ had a significantly greater proportion of cocaine-free urine samples than either the vaccinated subjects who had low antibody titers or the placebo group. Currently, a multi-site, double-blind, randomized clinical trial conducted in a sample of 300 cocaine-dependent subjects is about to be completed (www.clinicaltrials.gov NCT00969878) (Kinsey, Kosten, \& Orson, 2010; Kosten et al., 2002; Martell et al., 2005).

A novel immunotherapy approach against cocaine addiction is based on adenovirus gene transfer vectors, which are potent immunogens. This vaccine consists of linking the capsid protein of an adenovirus to the addictive substance (or an analog). The Ad gene transfer vectors are noninfectious and do not produce toxicity or immunosupression. This vaccine was created by covalently coupling the disrupted adenovirus ( $\mathrm{dAd}$ ) with a cocaine analog (GNC). It has been reported that mice that are administered cocaine, the $d A d 5 G N C$ vaccine can elicit the production of antibodies against cocaine which can sequester the cocaine in blood, thus, prevent its access to the brain. Moreover, these anticocaine antibodies appear to reverse the hyperlocomotor activity produced by the administration of cocaine (Hicks et al., 2011). Further research is being conducted to develop dAd5GNC for the treatment of cocaine dependence.

Monoclonal antibodies ( $\mathrm{mAb}$ ) may be helpful in reversing severe toxicity associated with cocaine overdose. The $\mathrm{GNC} 92 \mathrm{H} 2$ is an immunoglobuline $\mathrm{G}(\mathrm{IgG})$ with extended half-life that may sequester cocaine in blood and prevent 
its access to the brain. It appears that this vaccine has the capacity to redistribute cocaine from the brain to serum within the restricted timeframe of cocaine overdose. Further research needs to be conducted to determine the medical safety and therapeutic utility of $\mathrm{GNC} 92 \mathrm{H} 2$ for cocaine overdose (Treweek, Roberts, \& Janda, 2011)

Human plasma butyrylcholinesterase (BChE) contributes to the normal metabolism of cocaine and is being investigated for the treatment of cocaine dependence and overdose (Gorelick, 1997). BChE metabolizes cocaine into ecgonine methyl ester and benzoic acid, which have little toxicity and lack rewarding actions. Natural BChE slowly hydrolyzes cocaine; however, computationally guided mutations of the enzyme can increase the efficiency to metabolize cocaine. The hypothesis is that a highly-efficient engineered $\mathrm{BChE}$ ( $\mathrm{e}-\mathrm{BChE}$ ) may be able to metabolize cocaine in the blood before enters the central nervous system. That way, in the case of cocaine dependence, a treatment with e-BChE may prevent the access of cocaine to the brain and eventually extinguish the brain reward mechanisms associated with the addiction. In the case of overdose, the administration of $\mathrm{e}-\mathrm{BChE}$, if it is soon enough, may prevent the central nervous system complications associated with cocaine overdose (Brimijoin et al., 2008; Zheng et al., 2008).

TV-1380, an e-BChE, is being developed by Teva Pharmaceuticals Ltd. TV-1380 is a fusion of the mutant BChE enzyme with human serum albumin with extended catalytic activity, prolonged plasma half-life, and good stability. Studies suggest that TV-1380 has no adverse cardiovascular and respiratory reactions and appears to attenuate the cardiovascular effects produced by cocaine in monkeys (Godin et al., 2012). Studies to determine the safety and efficacy of TV-1380 for the treatment of cocaine dependence should be conducted.

\section{Methamphetamine}

Immunotherapeutic approaches to methamphetamine and amphetamine addiction and overdose also appear promising. Several groups are investigating vaccines and monoclonal antibodies to treat these conditions ( Carroll et al., 2009; Duryee et al., 2009; Gentry et al., 2010; Gentry, Ruedi-Bettschen, \& Owens, 2009; Moreno, Mayorov, \& Janda, 2011).

Duryee et al reported a methamphetamine (meth) vaccine with a meth hapten covalently to a selective molecular adjuvant (EP54). Rats treated with this vaccine generated serum antibody titers against meth and increased meth selfadministration, which the authors interpret as the result of pharmacokinetic antagonism (Duryee et al., 2009). Moreno et al report the systematic generation of a series of haptens designed to target methamphetamine. Vaccination of mice with meth immunoconjugates showed high antibody titers and high affinity for three particularly promising formulations (Moreno et al., 2011).

Gentry et al found that anti-meth-mAbs are able to antagonize the locomotor effects of meth in rats. The higher affinity $\mathrm{mAb}$ is more effective in reducing meth- induced locomotor effects than was the low affinity mAb. In addition, this $\mathrm{mAb}$ also decreases meth-induced elevations in blood pressure and heart rate. Therefore, a high affinity antimeth-mAb may be prevent neurotoxicity and cardiovascular complications associated with meth overdose (Gentry et al., 2009).

One of the advantages of anti-meth-mAb is that they provide concentrations that can be sustained for long periods of time (e.g., 6-12 months). This characteristic may be useful for therapeutic purposes because the long-term effects may facilitate a behavioral modification that may extinguish the brain mechanisms of addiction of addicted patients. One of the major limitations of the Mab is the high cost of production and the potential of producing antigenicity when the $\mathrm{mAb}$ are used for extended periods of time (Gentry et al., 2010). Recently, investigators began clinical trials of this $\mathrm{mAb}$ for the treatment of methamphetamine dependence.

\section{Conclusions}

Biologics are an innovative and exciting approach to treat drug addiction and overdose. However, they alone will unlikely be the panacea. All biologic treatments, like any pharmacotherapies, must be used in the context of a therapeutic milieu and in conjunction with supportive psychosocial interventions. One of the advantages of biologics is the possibility of boosting their effect by concurrently using medications. Given that biologics do not reach the brain, the possibility of adverse interactions with medications that affect the CNS is likely minimal. Therefore, it is possible that in the future the treatment of some forms of drug addictions or overdose may involve the combination of biologics and some sort of pharmacotherapy with an evidence-based effective psychosocial intervention.

Given the public health burden of the drug addiction and overdose, there is clearly an urgent need for safe and effective treatments. It is known that drug addicts have poor treatment adherence, which can often explain the lack of success of treatment outcomes. Ideally, an effective biologicbased therapy should be provided with a compound that has long-term action and require infrequent administration and, thus, increase the probability of successful outcomes. Some of the vaccines, $\mathrm{mAb}$ and $\mathrm{BCh}$ have a relatively extended effect but in all cases a boost or re-administration of the compound is required. For example, it has been shown that the anti-cocaine and anti-nicotine vaccines required the administration of boosting doses in order to maintain acceptable levels of antibodies. So, a challenge to improve the efficacy of such vaccines is not only the ability to produce acceptable antibody levels but, very important, to maintain the titers at levels enough to block the drug of abuse for the extended periods of time required to extinguish the behavioral aspect of the addiction.

One of the characteristics of biologics against addictions is their specificity against a target drug or class of drugs. This 
can be an advantage or a disadvantage. It is an advantage because there is a low risk of cross-reactivity with other medications that may have a therapeutic effect. For example, the heroin vaccine may be effective in producing antibodies against heroin but will not react with other medications such as buprenorphine or oxycodone, which may be needed by the patient for the treatment of opiate addiction or pain, respectively. It is a disadvantage because addicts often use multiple drugs or switch from one drug to another depending on what is available to control their drug craving or withdrawal. So, for example, a patient receiving the anti-heroin vaccine may start using illicit buprenophine in response to intense opioid craving. In this case, the vaccine will not have an effect against buprenophine and the patient may end up substituting for other addiction. To address this issue, investigators are developing poly-valent vaccines that may eventually be effective against a multiple drugs of abuse. Therefore, a biologic with efficacy against multiple drugs of abuse would be most desirable.

Given the nature of the molecules of biologics, the medical safety concerns may be different than those usually present in traditional medication studies. For vaccines, the reliance on the immune system for the production of antibodies requires that vaccinated individuals have a system that is able to respond and produce sufficient levels of antibodies to block the access of the drug of abuse to the brain. Therefore, individuals with immunodeficiencies, poor nutrition, or chronic and debilitating medical conditions may not be good candidates for this type of therapy. On the other hand, biologics, particularly vaccines, may elicit immune reactions that may range from an innocuous skin rash to severe anaphylactic shock. However, given that, in principle, biologics do not penetrate the CNS, it is expected that they will be exempt from adverse reaction at the CNS level. Therefore, health care providers should be aware of the specific medical safety features of the different biologic therapies.

In addition to the technical challenges in the development of vaccines, there are challenges associated with the methods to evaluate the clinical significance or treatment success of biologic treatments. Currently, the only endpoint that is acceptable for clinical trials of pharmacotherapies for drug addictions is drug use abstinence. It is widely documented that this is an outcome that may be difficult to achieve. Moreover, the only objective and practical method to evaluate drug use is based on urine toxicology testing for drugs of abuse. These methods, although very useful, sometimes does not capture the full clinical picture of the patient's drug use problem. Therefore, clinical trials with more realistic endpoints as well as sensitive and specific clinical markers of the patient's changes of the disorders are greatly needed. This way, when testing biologics, investigators will be able to achieve attainable goals and eventually obtain prescription approval by regulatory agencies.

Finally, the development of biologics for addiction treatment poses important ethical and legal challenges. The use of new technologies to develop biologics may raise concern about the safety of these products to be tested for the first in humans. Some of the new biologics may fall in the category of what is now called "dual use research concern" (DURC). This is defined as "life sciences research that, based on current understanding, can be reasonably anticipated to provide knowledge, information, products, or technologies that could be directly misapplied to pose a significant threat with broad potential consequences to public health and safety, agricultural crops and other plants, animals, the environment, or national security." On March of 2012, the United States Government issued a policy for oversight of life sciences dual research of concern. It is likely that some research on anti-addiction biologics may fall under the DURC category. Moreover, biologics can be expensive and only those who can afford them may be able to benefit from getting treatment with these products.

Although there are challenges associated with the development of biologics as treatments for drug addictions and overdose, more research should be conducted to advance those compounds that are already available as well as to discover new methods to improve the safety and efficacy of biologics. There is a great need of vaccines that can elicit high levels of antibody titers, adjuvants that can improve their immunogenecity, nanotechnologies to improve the specificity and efficiency of production of vaccines, biologics with long-term effects that can require few administrations, as well as highly efficient pharmacokinetic approaches, among others. Given the accelerated pace of this area of research, it is expected that in the near future there will be safe and effective biologics that health care providers can use to treat drug addictions and overdose.

\section{References}

Anton, B., \& Leff, P. (2006). A novel bivalent morphine/heroin vaccine that prevents relapse to heroin addiction in rodents. Vaccine, 24, 3232-3240.

Anton, B., Salazar, A., Flores, A., Matus, M., Marin, R., Hernandez, J. A., \& Leff P. (2009). Vaccines against morphine/heroin and its use as effective medication for preventing relapse to opiate addictive behaviors. Human Vaccine, 5, 214-229.

Bonese, K. F., Wainer, B. H., Fitch, F. W., Rothberg, R. M., \& Schuster, C. R. (1974). Changes in heroin self-administration by a rhesus monkey after morphine immunisation. Nature, 252, 708-710.

Brimijoin, S., Gao, Y., Anker, J. J., Gliddon, L. A., LaFleur, D., Shah, R.,... Carroll, M. E. (2008). A cocaine hydrolase engineered from human butyrylcholinesterase selectively blocks cocaine toxicity and reinstatement of drug seeking in rats. Neuropsychopharmacology, 33, 2715-2725.

Carroll, F. I., Abraham, P., Gong, P. K., Pidaparthi, R. R., Blough, B. E., Che, Y.,... Owens, S. M. (2009). The synthesis of haptens and their use for the development of monoclonal antibodies for treating methamphetamine abuse. Journal of Medicinal Chemistry, 52, 7301-7309.

Carroll, M. E., Gao, Y., Brimijoin, S., \& Anker, J. J. (2011). Effects of cocaine hydrolase on cocaine self-administration under a PR 
schedule and during extended access (escalation) in rats. Psychopharmacology (Berl), 213, 817-829.

Celtic Pharma: (2012) Study of TA-NIC to Assess the Efficacy and Safety of the Vaccine as an Aid to Smoking Cessation http:// clinicaltrials.gov/ct2/show/NCT00633321.

Celtic Pharma: (2012) TA-NIC Nicotine Dependence http://www. celticpharma.com/theportfolio/ta-nic.html.

Cytos Biotechnology: (2012) New clinical study started with the nicotine vaccine NICO02 http://www.cytos.com/userfiles/file/ Cytos_Press_E_101105.pdf.

Cytos Biotechnology: (2012) NIC002 (formerly CYT002-NicQb): a Novel Vaccine for Nicotine addition http://www.cytos.com/doc/ NIC002_Nicaddiction_Facts_August07.pdf.

de Villiers, S. H., Lindblom, N., Kalayanov, G., Gordon, S., Baraznenok, I., Malmerfelt, A.,... Svensson, T. H . (2010). Nicotine hapten structure, antibody selectivity and effect relationships: results from a nicotine vaccine screening procedure. Vaccine, 28, 21612168.

de Villiers, S. H., Lindblom, N., Kalayanov, G., Gordon, S., Malmerfelt, A., Johansson, A. M., \& Svensson, T. H. (2002). Active immunization against nicotine suppresses nicotine-induced dopamine release in the rat nucleus accumbens shell. Respiration, 69, 247-253.

Duryee, M. J., Bevins, R. A., Reichel, C. M., Murray, J. E., Dong, Y., Thiele, G. M., \& Sanderson, S. D. (2009). Immune responses to methamphetamine by active immunization with peptide-based, molecular adjuvant-containing vaccines. Vaccine, 27, 2981-2988.

Fox, B. S., Kantak, K. M., Edwards, M. A., Black, K. M., Bollinger, B. K., Botka, A. J.,... Briner, T. J. (1996). Efficacy of a therapeutic cocaine vaccine in rodent models. Nature Medicine, 2, 1129-1132.

Gao, Y., Orson, F. M., Kinsey, B., Kosten, T., \& Brimijoin, S. (2010). The concept of pharmacologic cocaine interception as a treatment for drug abuse. Chemico-Biological Interactions, 187, 421-424.

Gentry, W. B., Ruedi-Bettschen, D., \& Owens, S. M. (2009). Development of active and passive human vaccines to treat methamphetamine addiction. Human Vaccine, 5, 206-213.

Gentry, W. B., Ruedi-Bettschen, D., \& Owens, S. M. (2010). Anti-(+)methamphetamine monoclonal antibody antagonists designed to prevent the progression of human diseases of addiction. Clininical Pharmacology and Therapeutics, 88, 390-393.

Godin, C. S., Shemesh-Davish, L., Sklair-Tavron, L., \& Rosenstock, M. (2012) TV-1380 (Albumin-Fused Mutated Bche) Attenuates the Cardiovascular and Respiratory Effects Induced by Cocaine in Cynomolgus Monkeys http://www.avanzalaboratories.com/ abstract/Teva\%20Poster\%20S0T\%202010.pdf.

Gorelick, D. A. (1997). Enhancing cocaine metabolism with butyrylcholinesterase as a treatment strategy. Drug and Alcohol Dependence, 48, 159-165.

Gorelick, D. A. (2012). Pharmacokinetic strategies for treatment of drug overdose and addiction. Future Medicinal Chemistry, 4, 227243.

Gu, F., Langer, R., \& Farokhzad, O. C. (2009). Formulation/preparation of functionalized nanoparticles for in vivo targeted drug delivery. Methods in Molecular Biology, 544, 589-598.

Hatsukami, D. K., Jorenby, D. E., Gonzales, D., Rigotti, N. A., Glover, E. D., Oncken, C. A.,... Rennard, S. I. (2011). Immunogenicity and smokingcessation outcomes for a novel nicotine immunotherapeutic. Clininical Pharmacology and Therapeutics, 89, 392-399.

Hicks, M. J., De, B. P., Rosenberg, J. B., Davidson, J. T., Moreno, A. Y., Janda, K. D.,... Crystal, R. G . (2011). Cocaine analog coupled to disrupted adenovirus: a vaccine strategy to evoke high-titer immunity against addictive drugs. Molecular Therapy, 19, 612-619.

Kantak, K. M. (2003). Anti-cocaine vaccines: antibody protection against relapse. Expert Opinion in Pharmacotherapy, 4, 213-218.

Kinsey, B. M., Jackson, D. C., \& Orson, F. M. (2009). Anti-drug vaccines to treat substance abuse. Immunology and Cell Biology, 87, 309-314.

Kinsey, B. M., Kosten, T. R., \& Orson, F. M. (2010). Anti-cocaine vaccine development. Expert Rev Vaccines, 9, 1109-1114.

Kosten, T. R., Rosen, M., Bond, J., Settles, M., Roberts, J. S., Shields, J.,... Fox, B. (2002). Human therapeutic cocaine vaccine: safety and immunogenicity. Vaccine, 20, 1196-1204.

Li, Q. Q., Luo, Y. X., Sun, C. Y., Xue, Y. X., Zhu, W. L., Shi, H. S.,... Lu, L. (2011). A morphine/heroin vaccine with new hapten design attenuates behavioral effects in rats. Journal of Neurochemistry, 119, 1271-1281.

Marsch, L. A. (1998). The efficacy of methadone maintenance interventions in reducing illicit opiate use, HIV risk behavior and criminality: a metaanalysis. Addiction, 93, 515-532.

Martell, B. A., Mitchell, E., Poling, J., Gonsai, K., \& Kosten, T. R. (2005). Vaccine pharmacotherapy for the treatment of cocaine dependence. Biological Psychiatry, 58, 158-164.

Montoya, I. (2008). [Immunotherapies for drug addictions]. Adicciones, 20,111-115.

Montoya, I. D. \& Vocci, F. (2008). Novel medications to treat addictive disorders. Current Psychiatry Reports, 10, 392-398.

Moreno, A. Y., Mayorov, A. V., \& Janda, K. D. (2011). Impact of distinct chemical structures for the development of a methamphetamine vaccine. Journal of the American Chemical Society, 133, 65876595.

Nabi Pharmaceuticals: (2012) NicVAX ${ }^{\circledR}$ (Nicotine Conjugate Vaccine) http://www.nabi.com/pipeline/pipeline.php?id=3.

Orson, F. M., Kinsey, B. M., Singh, R. A., Wu, Y., Gardner, T., \& Kosten, T. R. (2008). Substance abuse vaccines. Annals of the New York Academy of Sciences, 1141, 257-269.

Peterson, E. C., \& Owens, S. M. (2009). Designing immunotherapies to thwart drug abuse. Molecular Interventions, 9, 119-124.

Pravetoni, M., Keyler, D. E., Pidaparthi, R. R., Carroll, F. I., Runyon, S. P., Murtaugh, M. P.,... Pentel, P. R. (2012). Structurally distinct nicotine immunogens elicit antibodies with non-overlapping specificities. Biochemical Pharmacology, 83, 543-550.

Pravetoni, M., Keyler, D. E., Raleigh, M. D., Harris, A. C., LeSage, M. G., Mattson, C. K.,... Pentel, P. R. (2011). Vaccination against nicotine alters the distribution of nicotine delivered via cigarette smoke inhalation to rats. Biochemical Pharmacology, 81, 1164-1170.

Pravetoni, M., Le, N. M., Harmon, T. M., Tucker, A. M., Portoghese, P. S., \& Pentel, P. R. (2012). An oxycodone conjugate vaccine elicits drug-specific antibodies that reduce oxycodone distribution to brain and hot-plate analgesia. Journal of Pharmacology and Experimental Therapeutics, 341, 225-232.

Selecta Biosciences: (2012) Selecta Biosciences Initiates Phase 1 Clinical Study of SEL-068, a First-in-Class Synthetic Nicotine Vaccine for Smoking Cessation and Relapse Prevention http:// www.selectabio.com/news/recent-news/Selecta-BiosciencesInitiates-Phase-1-Clinical-Study-of-SEL-068.cfm.

Stowe, G. N., Vendruscolo, L. F., Edwards, S., Schlosburg, J. E., Misra, K. K., Schulteis, G.,... Janda, K. D. (2011). A vaccine strategy that induces protective immunity against heroin. Journal of Medicinal Chemistry, 54, 5195-5204.

Substance Abuse and Mental Health Services Administration. (2011). Results from the 2010 National Survey on Drug Use and Health: 
Summary of National Findings. NSDUH Series H-41, HHS. Publication No. (SMA) 11-4658. Rockville, MD: Substance Abuse and Mental Health Services Administration, 2011.

Treweek, J. B., Roberts, A. J., \& Janda, K. D. (2011). Immunopharmacotherapeutic manifolds and modulation of cocaine overdose. Pharmacology Biochemistry and Behavior, 98, 474-484.

U.S.Food and Drug Administration (1999). Regulation of Biological Products. 42USC262 [On-line]. Available: http://www.fda.gov/ RegulatoryInformation/Legislation/ucm149278.htm

Unknown: (2012) Swedish scientists working on Niccine, a vaccine to fight against $h$ ttp://healthvox.info/?p=33.

Volkow, N. D. (2010). Toward individualized treatment for substance abuse. Addiction Science and Clinical Practice, 5, 2.
Zhang, L., Gu, F. X., Chan, J. M., Wang, A. Z., Langer, R. S., \& Farokhzad, O. C. (2008). Nanoparticles in medicine: therapeutic applications and developments. Clinical Pharmacology and Therapeutics, 83, 761-769.

Zheng, F., Yang, W., Ko, M. C., Liu, J., Cho, H., Gao, D.,... Zhan. C. G. (2008). Most efficient cocaine hydrolase designed by virtual screening of transition states. Journal of the American Chemical Society, 130, 12148-12155.

Zheng, F., \& Zhan, C. G. (2009). Recent progress in protein drug design and discovery with a focus on novel approaches to the development of anti-cocaine medications. Future Medicinal Chemistry, 1, 515-528. 
